\title{
POR UMA UNIVERSIDADE ABERTA À PARTICIPAÇÃO DO IDOSO
}

\author{
TOWARDS A UNIVERSITY OPEN TO THE ELDERLY PARTICIPATION
}

\author{
Maria Liduína de Oliveira e Silva ${ }^{1}$ \\ Sidnei José Casetto ${ }^{2}$ \\ Elizabeth Gonzalez Gagliardi ${ }^{3}$ \\ Yara Aparecida de Paula ${ }^{4}$ \\ Rosilda Mendes ${ }^{5}$ \\ Ricardo Luís Fernandes Guerra ${ }^{6}$ \\ Tânia Maria Ramos de Godoi Diniz ${ }^{7}$ \\ Heliete Rodrigues Herrera ${ }^{8}$
}

\section{RESUMO}

Apresenta-se a reformulação de uma proposta de Universidade Aberta à Terceira Idade (UATI) ocorrida no campus Baixada Santista da Universidade Federal de São Paulo (UNIFESP), reconstituindo sua história e seu processo político-pedagógico na perspectiva dos princípios de ensino público e gratuito, de educação intergeracional e de integração dos idosos às atividades do campus. Apresentam-se também as características da cidade de Santos quanto à população de idosos, e discute-se o papel da universidade em relação a ela. O relato da experiência aponta para a possibilidade de uma UATI integrada ao campus, com baixo custo operacional e ampla participação universitária. Entretanto, também são relatadas dificuldades, como a ausência de espaços estáveis ou próprios para as aulas e guarda de materiais e arquivos. Por fim, apontam-se os horizontes que puderam se abrir com esta proposta, que parecem mostrar o potencial da UATI no favorecimento da vocação universitária pela pesquisa, pelo ensino e pela extensão.

PALAVRAS-CHAVE: Terceira idade. Idoso. Universidade Aberta à Terceira Idade. Educação intergeracional.

\section{ABSTRACT}

This paper presents a proposal for a recast of University of the Third Age (UATI) occurred on campus Baixada Santista, Federal University of São Paulo (UNIFESP), retracing its history and its pedagogical orientation and driving policies process from the perspective of public and free education, intergenerational integration, and participation of the older people in academic activities. It also contains the characteristics of the city of Santos as the elderly population, and discusses the role of the university in relation to it. The account of the experience points to the

\footnotetext{
${ }^{1}$ Coordenadora da Universidade Aberta da Terceira Idade do Campus Baixada Santista da Universidade Federal de São Paulo (UATI/BS), gestão 2014/15, professora do Curso de Serviço Social do campus Baixada Santista da Universidade Federal de São Paulo.

2 Professor do Departamento de Saúde, Clínica e Instituições do campus Baixada Santista da UNIFESP e ex-coordenador da UATI/BS, gestão 2012/13.

3 Secretária Executiva da UATI/BS da UNIFESP de 2006 a 2010 e de 2012 até os dias atuais.

${ }^{4}$ Coordenadora Adjunta (gestão 2014-2015) e coordenadora pedagógica da UATI/BS desde 2012.

${ }^{5}$ Professora do Departamento de Políticas Públicas e Saúde Coletiva do campus Baixada Santista da UNIFESP e membro do Conselho Gestor da UATI/BS.

${ }^{6}$ Professor do Departamento de Ciências do Movimento Humano do campus Baixada Santista da UNIFESP e membro do Conselho Gestor da UATI/BS.

${ }^{7}$ Professora do Departamento de Políticas Públicas e Saúde Coletiva do campus Baixada Santista da UNIFESP e membro do Conselho Gestor da UATI/BS.

${ }^{8}$ Presidente da Associação Exa-UATI e membro do Conselho Gestor da UATI/BS.

Serv. Soc. \& Saúde, Campinas, SP v.14, n.1(19), p. 27-38, jan./jun. 2015 ISSN 1676-6806
} 
possibility of an integrated UATI to the campus, with low operating costs and wide university engagement. However, difficulties are also reported, such as lack of stable or own spaces for classes and save materials and files. Finally, we point to the horizons that might be open to this proposal, that seem to show the potential of the UATI in fostering university vocation for research, education and services.

KEYWORDS: Seniors. Elderly. University of the Third Age. Intergenerational Education.

\section{INTRODUÇÃO}

No ano de 2011 o campus Baixada Santista da UNIFESP abriu vagas para a Universidade Aberta à Terceira Idade, mas a procura pelas inscrições era baixa, insuficiente para formar uma turma. Grande contraste com cinco anos antes, quando tudo começara, em que os interessados foram sorteados, tal era a diferença entre candidatos e vagas. $\mathrm{O}$ que teria provocado esta drástica diminuição de demanda? Entrementes ocorria, naquele ano de 2011, que, pela primeira vez, uma direção acadêmica do campus eleita pela comunidade tomasse posse. Surgia a oportunidade de reivindicarmos uma UATI afinada com o projeto político-pedagógico local, que não ficasse restrita ao formato da UATI do campus São Paulo.

O modelo existente era o de aulas organizadas por meio de palestras, em que predominavam temas da área de saúde, e, frequentemente, doenças. Nos primeiros anos a maioria dos palestrantes vinha de São Paulo. O curso era pago, havia uma taxa de inscrição e mensalidades. Esse dinheiro ajudava no orçamento do curso, como o prólabore dos professores e profissionais que vinham falar aos idosos. No final do ano, os alunos dividiam-se em grupos e elaboravam um trabalho acerca de algum dos temas pré-definidos pela coordenação. Pela exiguidade do espaço nos prédios da universidade, após algumas edições o curso passou a acontecer em uma escola da rede municipal de ensino, afastada do campus. Cada vez mais o curso ocorria sem ingerência, participação ou relação com os membros da comunidade unifespiana local.

A questão da existência de cursos pagos em uma universidade pública já havia sido levantada na Unifesp, tendo sido objeto de questionamento pelo Ministério Público em 2007. A universidade mantém diversos cursos de especialização pagos, e a UATI somava-se a eles. Não havia, por parte dos alunos da UATI, problematizações significativas a este respeito. As taxas e mensalidades não eram altas, sendo acessíveis à classe média local. De nosso ponto de vista, entretanto, havia aqui um problema éticopolítico relativo à missão da universidade pública e às atividades de extensão oferecidas à comunidade. Não era fácil justificar tal cobrança, na medida em que restringia o Serv. Soc. \& Saúde, Campinas, SP v. 14, n. 1 (19), p. 27-38, jan./jun. 2015 ISSN 1676-6806 
acesso a parte da população: para um número significativo de cidadãos tal despesa era proibitiva. Vale notar que a população de idosos de renda incompatível com este custo não reivindicava nenhuma participação na UATI. Se tomava conhecimento dela devia apenas dar-se conta de que se tratava de algo que não havia sido feita para si. Desse modo, o campus, indiretamente, participava desta escolha acerca de quais parcelas da população atender.

A questão não era simples sobretudo se consideradas as despesas a serem cobertas. A universidade recebe verbas do Ministério da Educação destinadas aos cursos de graduação. Outros recursos também têm finalidades definidas, mas nenhum deles é voltado diretamente para atividades de extensão, com a exceção de bolsas para alunos extensionistas. Colocava-se a questão de como pagar professores, transporte e outros custos inerentes a esta atividade. Neste raciocínio, uma justificativa para cobrar de quem usufruísse deste benefício seria não onerar todos por aquilo de que só a alguns favoreceria.

Este argumento é também utilizado amiúde por quem defende a cobrança do ensino público universitário: o cidadão que não usufrui dele não deveria pagar por ele com seus impostos. Um dos problemas deste argumento, a nosso ver, é que ele identifica ausência de usufruto direto com ausência total de usufruto. Em contrapartida, podemos pensar que, se se tem uma universidade integrada com a comunidade na qual se insere, inúmeros são os benefícios que produz aos cidadãos que a sustentam, como por exemplo, só para citar o mais básico, formar profissionais competentes para servi-la. Oferecer atividades de extensão seria outro possível. Mas também seria possível perceber naquela lógica um pressuposto ético-político, a saber, o de que cada cidadão, tomado como indivíduo, é o único responsável por si mesmo. Outra perspectiva possível, solidária, comunitária, de direitos e deveres compartilhados, aponta para o benefício comum de bens e serviços públicos voltados para a diversidade da população. Não estaríamos sendo lesados por ajudar a sustentar necessidades de setores específicos porque haveria reciprocidade, e o benefício destes setores se propagaria, indiretamente, aos demais.

Estaríamos, portanto, justificados em defender uma UATI isenta de taxas e mensalidades, acessível à população mais socialmente vulnerável. Mas restava saber como viabilizá-la, com que dinheiro pagar os professores, e se poderíamos contar com a participação voluntária de docentes, técnicos e estudantes do campus. Esta última alternativa permitiria reduzir o custo fixo específico a praticamente zero. 
Pensávamos numa UATI que fosse integrada ao campus, em que idosos pudessem conviver com os jovens em sua experiência universitária. Outras universidades ofereciam vagas nos cursos de graduação, o que poderíamos também fazer. Não sabíamos, porém, se haveria adesão à ideia por parte de nossos docentes. Mas gostaríamos de manter as aulas específicas para os alunos da UATI, ajudando a estreitar laços entre os participantes. A realização de trabalhos em grupo parecia-nos valiosa, mas julgávamos que seria mais produtiva se os alunos pudessem decidir pelo tema que mais lhes mobilizasse investigar.

Enfim, pensávamos em romper com o modelo de UATI herdado, mas também em dar continuidade a ele. Haveria que se aproveitar a experiência anterior, preservando seus aspectos valiosos, inclusive o fato de haver iniciado o projeto no campus, mas inserindo-lhe novos princípios, como o da não cobrança de taxas e mensalidades e a integração com a graduação. Não se tratava de reinventar a UATI, ao mesmo tempo em que precisávamos recriá-la.

\section{A universidade e a sociedade santista: a participação do idoso nos processos de conhecimentos e mudanças sociais}

O reconhecimento de que a academia teria algo a oferecer e a receber dos idosos têm se fortalecido nas últimas décadas, quando as experiências de "universidade aberta" voltadas a este público foram ocorrendo pelo Brasil afora. Como relatado por Veras \& Costa (2004) o movimento por universidades abertas à terceira idade surgiu no pais há mais de trinta anos, na década de 1980, tendo como referência as experiências de universidades europeias, especialmente na França, que já desenvolviam iniciativas dessa natureza desde os anos de 1960 com objetivos iniciais voltados ao favorecimento de atividades culturais e sociabilidade. Mais tarde, acrescentaram-se o desenvolvimento de estudos e pesquisas sobre o envelhecimento, e, já nos anos 1980, a elaboração de programas educacionais mais amplos direcionados a aposentados.

A partir dos anos de 1990 várias universidades abertas à terceira idade foram implantadas no Brasil seguindo os modelos mais diversos, mas com propósitos comuns de incentivar a autonomia e o resgate da cidadania, rever os preconceitos em relação ao envelhecimento e promover a reinserção social (VERAS \& COSTA, 2004). Considerase que os idosos, como os jovens, são sujeitos que protagonizam suas sociabilidades e têm plenas condições de continuar aprendendo, produzindo e transmitindo conhecimentos, assim como de transformar limites em ações alternativas, produzindo Serv. Soc. \& Saúde, Campinas, SP v. 14, n. 1 (19), p. 27-38, jan./jun. 2015 ISSN 1676-6806 
mudanças culturais e sociais. Pressupõe-se que o encontro entre idosos e jovens pode ser de grande valor para ambas gerações, pelas chances de compreensão de "raízes" e "frutos" de gerações, assim como pelos deslocamentos mútuos de convicções e valores. Desta forma, a presença dos idosos na vida universitária tenderia a produzir tensões benéficas à formação profissional e às mudanças de mentalidades, uma vez que estas são favorecidas por questionamentos e revisões permanentes. Ademais, grande número de pesquisas no campo da saúde tem se voltado para os anos de envelhecimento, de maneira que a participação de idosos na universidade vem se constituindo em importante parceria na elaboração do conhecimento científico e produção nas relações sociais na sociedade. Evidência disso é o fato de que uma busca no banco de dados da Biblioteca Virtual em Saúde com os descritores "older people" e "health" apresentou mais de 3.700 trabalhos publicados nos últimos 10 anos, com aumento médio, a cada ano, de $14,4 \%$ das publicações.

Nas últimas décadas, os indicadores de saúde e de qualidade de vida apontam para significativa melhoria das condições de vida das populações em muitos países do mundo; doenças foram erradicadas e houve um aumento na sobrevida, o que elevou a expectativa de vida, no caso brasileiro, dos 33,4 anos em 1910 para os 73,1 em 2010 (BRASIL, 2010). Caracterizado como um país jovem, o Brasil está mudando seu perfil demográfico de forma muito rápida. Há no Brasil, hoje, em torno de 23 milhões de idosos. A população de idosos (60 anos ou mais) na Baixada Santista cresceu 44,84\% nos últimos dez anos mais do que a média do Estado de São Paulo $(43,84 \%)$ e do Brasil (41,65\%). A região contabiliza hoje em torno de 151 mil pessoas nessa faixa etária (BRASIL, 2010). Em números absolutos, o número de idosos em Santos passou de 65.200, em 2000, para 80.353 habitantes em 2010, o que significa que de cada cinco moradores da cidade, um tem mais de 60 anos de idade.

Em consonância, o futuro dos idosos tem sido considerado nas políticas públicas atuais, na mudança da sensibilidade brasileira em relação ao envelhecimento e no modo como os indivíduos se preparam para as etapas mais avançadas da vida. Em 2003 foi promulgada a lei 10.741, conhecida como Estatuto do Idoso, que define direitos deste segmento populacional, configurando uma proteção social (BRASIL, 2003). Outras leis e políticas locais, estaduais e nacionais poderiam ainda ser delineadas para encorajar idosos a terem uma participação social ativa.

No entanto, o idoso tende a ser visto pela perda da capacidade laborativa, pela improdutividade e pela incapacidade, passando a ser socialmente descartável, a despeito Serv. Soc. \& Saúde, Campinas, SP v.14, n.1(19), p. 27-38, jan./jun. 2015 ISSN 1676-6806 
das reservas intelectuais, afetivas, espirituais e estéticas acumuladas pela experiência vivida cuja densidade não corresponde às limitações de um corpo mais ou menos fragilizado e vulnerável, dependendo das condições da vida pregressa (SILVA, 2011, p. 2-3).

Alterações funcionais, associadas ao aumento da idade e a doenças mentais e crônico-degenerativas, provavelmente são potencializadas pelo recolhimento progressivo - e frequentemente involuntário - do idoso. Daí a importância desta população manter-se participante, em boas condições de autonomia e procurando novas inserções, de modo a explorar os potenciais físico, cognitivo e afetivo de que dispõe e prevenindo doenças. Entretanto, ainda que haja um discurso favorável aos idosos na sociedade santista e brasileira e uma tendência de crescimento de implementação de políticas públicas para essa parcela da população, são ainda observadas práticas reforçadas ora pelo paternalismo, ora pelo assistencialismo, que não oferecem um lugar social e cultural voltado para a terceira idade, bem como o reconhecimento do idoso como agente social que permita a ele outros modos de inserção mais inclusivos e formativos (OLIVEIRA, 2007). Nesta direção, trabalhos importantes têm sido desenvolvidos em torno da proposta da co-educação entre gerações, ou da educação intergeracional, procurando reunir jovens e idosos (FERRIGNO, 2003).

A proposta da Universidade Aberta à Terceira Idade que apresentamos aqui constitui-se como um projeto de extensão da Universidade Federal de São Paulo, que busca desenvolver sua função social, realizada por meio de um conjunto de ações dirigidas aos idosos. Tal projeto reafirma o Plano Nacional de Extensão, que tem como centralidade a efetivação de ações sociais, educativas e culturais diante das demandas da sociedade, estando à frente da universidade na defesa, garantia e promoção dos direitos dos idosos, particularmente em Santos, bem como na garantia dos valores democráticos de igualdade. Desse modo, a extensão procura ser um instrumento de inserção e mudanças sociais.

\section{A proposta político-pedagógica da UATI/BS: uma aposta no processo de aprendizagens intergeracionais entre idosos e jovens}

A elaboração de um novo projeto político-pedagógico da UATI para o campus estava decidida, mas precisava ser feita. Divulgamos então uma chamada para docentes e técnicos interessados em participar deste processo. Alguns se a proximaram e, em Serv. Soc. \& Saúde, Campinas, SP v. 14, n. 1 (19), p. 27-38, jan./jun. 2015 ISSN 1676-6806 
reuniões periódicas fomos tecendo, durante um semestre em que não houve a UATI, a nova proposta. Uma participação importante foi a da Associação EXAUATI, associação de ex-alunos que se formou após a primeira turma e mantinha atividades semanais para ex-alunos desde então. Com este grupo, elaboramos um projeto de extensão que tramitou pelas instâncias colegiadas do campus e pôde iniciar suas atividades em 2012. Com ele, constituímos um Conselho Gestor, formado por docentes, técnicos e estudantes extensionistas, além de representantes dos alunos (um de cada turma) e um representante da EXA-UATI. Este conselho reúne-se mensalmente, escolhe a coordenação da UATI e delibera sobre o andamento das atividades; o Conselho é aberto ao ingresso de novos integrantes.

Desenvolvemos uma proposta político-pedagógica com os alunos acima de 60 anos, centrada em processos de aprendizagens e convivência intergeracional, entre jovens estudantes de seis cursos de graduação (Educação Física, Fisioterapia, Nutrição, Psicologia, Serviço Social e Terapia Ocupacional) e os próprios idosos. Estabelecemos como objetivos: inserir os idosos na dinâmica universitária do campus, pela participação destes em atividades de ensino, extensão e pesquisa, especificamente desenvolvidas para eles ou compartilhadas com os jovens, estudantes de graduação; proporcionar aos idosos a oportunidade de cursar, conviver e contribuir com módulos dos seis cursos de graduação na área de saúde oferecidos no campus; desenvolver um programa de ensino e atividades específicas para a turma de idosos; favorecer a participação dos idosos nas diversas atividades abertas do campus, incluindo extensão e pesquisa.

A UATI/BS mantém duas turmas, sendo uma na unidade central do campus, e outra funcionando no Centro de Convivência da Zona Noroeste, ambas com 50 alunos. Esta última turma é organizada em parceria com a Prefeitura de Santos. É necessário esclarecer esta aparente contradição em abrir uma turma da UATI situada em um prédio fora do campus, considerando um projeto político-pedagógico que se pretende integrador. É que percebemos que, mesmo não cobrando taxas e mensalidades, os inscritos, na sua ampla maioria, eram idosos de bairros de classe média da cidade. Concluímos que, de fato, não havíamos contemplado os idosos de menor renda. Imaginamos que um obstáculo era a distância e locomoção. A solução pensada foi a de ir até bairros mais afastados e com população com características de vulnerabilidade social. A Zona Noroeste, em Santos, é uma região com este desenho, e dispõe de um Centro de Convivência de Idosos que estava disposto a fazer esta parceria conosco. As atividades específicas (como se explica a seguir) passaram a ser realizadas lá, mas a Serv. Soc. \& Saúde, Campinas, SP v.14, n.1(19), p. 27-38, jan./jun. 2015 ISSN 1676-6806 
participação em atividades da vida universitária também é oferecida a eles. Um outro desafio são os idosos moradores de cortiços do Centro de Santos, região contígua à unidade central da UNIFESP, cujo obstáculo não é a distância geográfica, mas a possível crença de que não poderiam ter acesso à universidade. Vencer este limite configura-se como uma perspectiva futura, como apontado no próximo item.

Uma das questões que tivemos que enfrentar foi quanto ao analfabetismo. Surgiu a questão relativa ao acesso à UATI dos idosos com pouco ou nenhum grau de escolaridade. Afinal, há o uso de linguagem escrita em diversos momentos, como em manuais, na elaboração de trabalhos e textos etc. Decidimos, porém, que a ausência de domínio da linguagem escrita não seria critério de exclusão; que os analfabetos seriam aqueles cidadãos privados da oportunidade de aprender e que poderíamos agora lhes oferecer um banco universitário, lugar em que nunca puderam entrar nestas condições, bastando fazer adaptações quando isso fosse necessário.

A vida universitária do aluno da UATI ocorre por meio do estímulo a convivências entre idosos e jovens, sendo que o idoso participa em aulas da graduação, atividades de extensão e pesquisa, estudos, oficinas e encontros com estudantes, docentes e técnicos. As atividades estão organizadas em três tipos: as específicas, as eletivas (juntamente com os estudantes de graduação em sala de aula e em outros projetos de extensão) e as complementares (oficinas, cursos, etc.).

As específicas são exclusivas para os estudantes UATI/BS. São aulas que acontecem toda sexta-feira, na unidade da Silva Jardim e CECONV Zona Noroeste, das $14 \mathrm{~h}$ às $17 \mathrm{~h}$. As eletivas são atividades, dentre muitas, que o idoso pode escolher para cursar. Ao menos uma delas deve ser realizada durante o ano. São duas possibilidades: módulos da graduação e projetos de extensão. Os módulos da graduação são aulas regulares para estudantes dos cursos (Educação Física, Fisioterapia, Nutrição, Psicologia, Serviço Social e Terapia Ocupacional) de graduação do campus, os quais ofertam vagas para os estudantes da UATI, promovendo o aprendizado intergeracional. O idoso pode escolher e cursar um destes módulos, de acordo com seu interesse, preferência e disponibilidade. Para a participação no módulo, a frequência às aulas é fundamental, mas não é necessário fazer provas ou trabalhos escritos. Por outro lado, estimula-se a participação em atividades de grupo e seminários.

A segunda possibilidade são os projetos de extensão, que são ações da universidade dirigidas à comunidade. São organizadas por professores, técnicos e 
estudantes. Em geral, envolvem estudantes de cursos diversos, e podem acontecer em várias regiões da cidade, como o centro, a zona noroeste, etc. Cada projeto ocorre em horários e locais diferentes.

As atividades complementares são livres e ocorrem fora dos horários das atividades específicas e eletivas, em diferentes lugares de aprendizagem. Geralmente acontecem no formato de oficinas, as quais vêm complementar a formação acadêmica dos estudantes uatianos. Temos oferecido, nesta categoria, oficinas de iniciação à informática e de inglês.

O certificado do curso é oferecido a quem frequenta, no mínimo, $75 \%$ das atividades específicas e uma eletiva, além de elaborar um trabalho em grupo, no primeiro semestre e, um trabalho individual, no segundo semestre. O curso tem duração anual.

Sem verbas para pagamento dos professores, não sabíamos se teríamos interessados em oferecer aulas aos idosos. Mas bastou divulgar a possibilidade para que docentes, técnicos e estudantes do campus se voluntariassem com seus conhecimentos e habilidades. Desde então não temos tido dificuldade em preencher as atividades específicas; ao contrário, ocorre mais oferta que aulas disponíveis, de modo que a seleção tem sido inevitável. As vagas em módulos da graduação e projetos de extensão também têm sido oferecidas em boa quantidade, permitindo a escolha pelos alunos da UATI. Cursos mais longos, como o citado de iniciação à informática ou inglês, também têm sido oferecidos e alojados como atividades complementares.

Com este projeto, desde a primeira turma passamos a ter muito mais candidatos que vagas. Prevendo esta possibilidade, tivemos que decidir qual critério usar. Em edições anteriores havia sido utilizado o sorteio, mas a aleatoriedade não nos satisfazia como recurso. Propusemos então a seleção pela idade: os mais velhos teriam preferência. Este critério, objetivo, permitiria aos não contemplados a compreensão imediata da razão e ainda a percepção de que sempre teriam mais chance nas turmas seguintes. Desde então temos usado este critério e a divulgação das datas de nascimento dos cinquenta convocados em cada turma.

\section{À GUISA DE CONCLUSÃO: DIFICULDADES E PERSPECTIVAS}

Os processos de sociabilidades e aprendizagens intergeracionais constituem-se e resultam da relação de troca de saberes entre estudantes, extensionistas, técnicos, 
professores e comunidade; da interação entre sujeitos, nas quais os participantes não são passivos em sua formação e em sua relação com o conhecimento, mas sim intérpretes e protagonistas de seu tempo.

A experiência das últimas três turmas permitiu observar o desenvolvimento de sociabilidades e integração entre os estudantes de graduação e os da UATI; a participação dos idosos com o cotidiano dos cursos e da universidade; um sentimento de inserção social; a possibilidade de ressignificar conteúdos; o desenvolvimento do senso crítico e o desejo pela síntese/registro de sua vivência acadêmica.

Percebemos a importância do fortalecimento das relações entre a universidade e a comunidade; da articulação de ações integradas com a Secretaria de Assistência Social, com a Associação dos Ex-alunos da UATI/BS e organizações que atuem na defesa da promoção dos direitos da pessoa idosa. Mas ainda precisamos estreitar a relação com os cursos de graduação; potencializar e aperfeiçoar a formação intergeracional; desenvolver instrumentos de planejamento, acompanhamento e avaliação desta proposta pedagógica.

Embora a UATI/BS esteja incorporada na estrutura da universidade como um projeto de extensão, ainda assim padece de falta de cultura institucional e de infraestrutura que a compreenda constituinte, parte integrante do campus. Ainda não tempos um espaço de trabalho e uma sala de aula garantida para as atividades específicas. Acontece com certa frequência que, para possibilitar alguma atividade da graduação, a reserva da sala para os encontros semanais específicos da UATI seja deslocada para outros espaços, inclusive o saguão do prédio. Há também dificuldades quanto à acessibilidade: amiúde os elevadores deixam de funcionar, restando aos idosos longas escadas. A instituição precisa discutir e criar alternativas para acolher pessoas longevas; neste ano (2015), por exemplo, a UATI/BS conta com uma idosa de 92 anos.

Por outro lado, ganha aderência, agrega profissionais e extensionistas com a causa e em sua operacionalização, especialmente as ações relacionadas ao apoio e ações pedagógicas. Assim conta com docentes, discentes, técnicos, ex-alunos e outros profissionais de fora da Instituição que prestam serviço voluntariamente, e que têm um pertencimento com esta causa social, reafirmando um protagonismo cotidiano com um trabalho árduo, mas prazeroso, e que produz transformações, por pequenas que sejam.

Nesta direção, a UATI/BS adota perspectivas para um futuro não muito distante, como as listadas abaixo: 
- Oferecer um local adequado para as atividades curriculares e atividades complementares: criar um ambiente favorável ao aprendizado, capaz de ajustar às necessidades e cuidados necessários para atender ao público idoso;

- Propiciar aos idosos participarem da elaboração da programação: a opinião dos idosos quanto à área de seu interesse norteia uma programação mais direcionada às suas expectativas;

- Qualificar os professores e outros colaboradores para o trabalho com o idoso: trabalhar com idosos demanda conhecimento prévio de várias áreas;

- Atender aos idosos moradores dos bairros de maior vulnerabilidade social do entorno da Universidade: interagir com o local onde está inserida a Universidade, próxima de uma região de cortiços;

- Favorecer a participação do idoso como sujeito político, ajudando a organizar debates, palestras, recepção aos calouros, mediação em conflitos, realização de atividades festivas, participação no Conselho do Idoso, entre outras;

- Estimular grupos de estudos voltados à reflexão sobre questões relacionadas aos idosos, seu direitos e deveres; o envelhecimento populacional no Brasil e no mundo; as políticas públicas de atenção aos idosos; o desafio social que o Brasil irá enfrentar com o aumento da população de idosos; entre outros;

- Criar um portal de periódico eletrônico para reunir as publicações acadêmicas/científicas (artigos, resumos, resenhas, debates, pôsteres e outros) editadas na Universidade pelos professores, técnicos, estudantes de diversas áreas, relativas ao envelhecimento;

- Promover parcerias com outros órgãos, instituições, pessoas e colaboradores: com a escassez de recursos o melhor caminho são as articulações e alianças;

Por fim, embora saiba-se das dificuldades apontadas, sobretudo do ponto de vista da infraestrutura, a aposta político-pedagógica é maior nas perspectivas, o que nos mobiliza a sermos propositivos em torno do compromisso, do trabalho coletivo e na defesa e promoção dos direitos humanos dos idosos na sociedade, neste processo de sintonia da universidade com a sociedade que a cria e mantém.

Recebido em 22.03.2015 - Aprovado em 22.05.2015 


\section{REFERÊNCIAS}

BRASIL. Ministério da Saúde. Estatuto do Idoso / Ministério da Saúde. 1. ed., 2. ${ }^{\text {a }}$ reimpr. Brasília: Ministério da Saúde, 2003.

BRASIL. Ministério do Planejamento, Orçamento e Gestão. Instituto Brasileiro de Geografia e Estatística. Censo demográfico 2010. Disponível em:

http://www.ibge.gov.br/home/estatistica/populacao/censo2010/ Acesso em: 16 Março 2015.

FERRIGNO, J. C. Co-educação entre gerações. Petrópolis, RJ: Vozes; São Paulo: SESC, 2003.

OLIVEIRA, R. C. S. O Processo histórico do Estatuto do Idoso e a inserção pedagógica na Universidade Aberta. Revista HISTEDBR On-line, Campinas, n.28, p. 278-286, dez. 2007.

SILVA, A. A. Viver com mais de 60 anos: a propósito da política social para as pessoas idosas. Serviço Social \& Saúde. UNICAMP, Campinas, v. X, n. 11, jul. 2011.

VERAS, R.P.; CALDAS, C.P. Promovendo a saúde e a cidadania do idoso: o movimento das Universidades da Terceira Idade. Ciência \& Saúde Coletiva, 9 (2): 423-432, 2004. 